\title{
A Pesquisa-experiência na Psicologia: Corpos, Afetos e Experiências em Territórios Urbanos ${ }^{1}$
}

\author{
Simone Maria Hüning ${ }^{1}$ \\ ${ }^{1}$ Universidade Federal de Alagoas, AL, Brasil.
}

\author{
Carlysson Alexandre Rangel Gomes ${ }^{2}$ \\ ${ }^{2}$ Universidade Federal de Alagoas, AL, Brasil.
}

\begin{abstract}
Resumo: Neste artigo temos como objetivo discutir como podemos promover outras formas de ocupação e produção do território acadêmico frente a questões emergentes na pesquisa em Psicologia em territórios urbanos. Apresentamos um debate teórico sobre como pesquisas relacionadas a territórios e territorialidades têm modificado teórica e epistemologicamente nosso campo de saber e suas formas de construção. Buscando inspiração nas derivas situacionistas damos ênfase à experiência produzida pelos corpos e afetos de quem pesquisa percorrendo a cidade. O caminhar pelos territórios urbanos como alternativa metodológica nos conduz a argumentar que nossos corpos compõem o processo de pesquisa tornando possíveis e ordenando a construção do conhecimento. Seguimos nossa reflexão sugerindo a pesquisaexperiência como estratégia de produção, de narrativa e problematização do conhecimento a partir de um corpo singular afetado pelos encontros ocorridos nos territórios: experienciar é o ponto de partida para um segundo momento, fundamental, quando se desloca a experiência para o território acadêmico e com ferramentas teórico-políticas coloca-se em análise a relação territorialidades-subjetividades.
\end{abstract}

Palavras-chave: Corpo, Afeto, Experiência, Territorialidades, Pesquisa.

\section{Experience-based Research in Psychology: Bodies, Affections and Experiences in Urban Territories}

\begin{abstract}
In this article we will discuss how we can promote other forms of occupation and production of academic territory in the face of emerging issues in psychology research in urban territories. We present a theoretical debate on how research related to territories and territorialities has theoretically and epistemologically changed our field of knowledge and its forms of construction. Inspired by situationist dérive, we emphasize the experience produced by the bodies and affections of those who investigate the city. Walking through urban territories as a methodological alternative leads us to argue that our bodies make up the research process, making possible and ordering the construction of knowledge. We continue our reflection suggesting experience-based research as a production strategy, of narrative and problematization of knowledge from a singular body affected by the encounters that occurred in the territories: living experience is the starting point for a second moment, fundamental, when the experience is shifted to the academic territory and, with theoretical-political tools, the relationship territorialities-subjectivities is analyzed.
\end{abstract}

Keywords: Body, Affections, Experience, Territorialities, Research.

\footnotetext{
${ }^{1}$ Financiamento: Bolsa Produtividade em Pesquisa CNPq - Processo 305364/2017-0; Bolsa de mestrado CAPES.
} 


\title{
La Investigación-experiencia en Psicología: Cuerpos, Afectos y Experiencias en Territorios Urbanos
}

\begin{abstract}
Resumen: En este artículo tenemos como objetivo discutir cómo podemos promover otras formas de ocupación y producción del territorio académico ante cuestiones emergentes en la investigación en psicología en territorios urbanos. Presentamos un debate teórico sobre cómo las investigaciones relacionadas a territorios y territorialidades han cambiado teórica y epistemológicamente nuestro campo de conocimiento y sus formas de construcción. Al buscar inspiración en las derivas situacionistas, enfatizamos la experiencia producida por los cuerpos $\mathrm{y}$ afectos de quienes investigan recorriendo la ciudad. Caminar por los territorios urbanos como alternativa metodológica nos lleva a argumentar que nuestros cuerpos componen el proceso de investigación, haciendo posible y ordenando la construcción del conocimiento. Seguimos nuestra reflexión sugiriendo la investigación-experiencia como estrategia de producción, de narrativa y problematización del conocimiento a partir de un cuerpo singular afectado por los encuentros ocurridos en los territorios:vivir la experiencia es el punto de partida para un segundo momento, fundamental, cuando la experiencia se desplaza hacia el territorio académico y, con herramientas teórico políticas, se analiza la relación territorialidades-subjetividades.
\end{abstract}

Palabras clave: Cuerpo, Afecto, Experiencia, Territorialidades, Investigación.

\section{Pesquisa e territórios acadêmicos}

A constituição de objetos, temas e, consequentemente, novas perspectivas teórico-metodológicas na Psicologia, é um processo constante e inacabado que, se por um lado é impulsionado pelas construções advindas do próprio campo científico; por outro lado, corresponde a uma série de demandas e pressões colocadas pelas problemáticas que se constituem em um determinado tempo. Tal perspectiva coloca a produção de conhecimento em conexão direta com a política, a história, a cultura e a sociedade, destituindo do campo científico uma primazia ou uma autonomia absoluta na determinação de seus focos de interesse e seus percursos. Desse modo, a vida social impõe rearranjos aos saberes, não apenas pela apresentação de novas questões a serem abordadas, mas pela necessidade de criação de outras abordagens para fenômenos emergentes.

Neste artigo, sustentamos que o social, ao nos apresentar novas demandas, orienta a constituição da Psicologia como disciplina e instaura territórios e territorialidades próprias para este campo disciplinar, estabelecendo, simultaneamente, mobilidades e formas de ocupação específicas. Diante disso, temos como objetivo discutir, a partir de uma reflexão teórica, como podemos promover outras formas de ocu- pação e de produção do território acadêmico frente a questões emergentes, especialmente aquelas vinculadas à pesquisa em territórios urbanos.

Denominamos aqui de território acadêmico todo um conjunto de produções que tradicionalmente é demarcado por fronteiras de saberes legitimados e dos seus objetos correspondentes - que constituem certa paisagem disciplinar (instituições como a universidade, associações acadêmico-científicas, periódicos científicos, temas de interesse etc.). Por territorialidades, entendemos os modos de circulação e de vida nesse espaço (titulações, especialidades, autoridades, teorias, metodologias, problemas, políticas de pesquisa e escrita etc.). A constituição de territórios e territorialidades acadêmicas envolvem, assim, aquilo e aqueles que podem figurar como agentes de um fazer científico reconhecido na Psicologia, bem como os temas de que ela deve se ocupar.

Especialmente desde o final dos anos 1990, num contexto de importantes modificações político-econômicas (tais como a globalização da economia e a emergência de novas tecnologias) e de transformações nas formas de vida nas cidades (como aumento da insegurança, problemas vinculados à circulação e reordenação urbanas) a Psicologia brasileira tem se voltado para o estudo de espaços urbanos. Nas pro- 
duções que se constituem a partir de então, ganham força a problematização e desnaturalização dos objetos e das dinâmicas sociais emergentes, de certo modo instaurando-se outras perspectivas de produção de conhecimento em Psicologia não mais vinculadas apenas a abordagens explicativas (Hüning, Guareschi, Reis, \& Azambuja, 2014).

Se as mudanças globais pautaram, naquele momento, uma nova agenda para a Psicologia, recentemente, no Brasil, acontecimentos como a realização de grandes eventos (Copa do Mundo de Futebol - 2014; e Jogos Olímpicos no Rio - 2016) e o agravamento de desigualdades sócio-econômicas e da violência urbana, convocaram, mais uma vez, a Psicologia a discutir esses territórios. Questões como mobilidade, exclusão, práticas higienistas, direito à cidade, imigração, movimentos sociais entre outras passaram a constituir-se como temas de interesse e produção científica da Psicologia, borrando fronteiras disciplinares com outros campos de saber tradicionalmente vinculados aos estudos da cidades e seus territórios e constituindo o urbano como território de circulação da Psicologia.

As questões emergentes do diálogo da Psicologia com o espaço urbano, especialmente nas últimas décadas, passam a compor o território acadêmico, suscitando outras formas de ocupação e circulação, portanto, outras territorialidades. Na reciprocidade das afetações entre território acadêmico e urbano, são forjadas experiências e políticas de pesquisa dissonantes dos modelos hegemônicos.

Nesses percursos, diferentes propostas teórico-epistemológicas-políticas têm sido compostas, modificando-se também o repertório e as ferramentas da Psicologia. A produção de conhecimento não se dá, assim, apenas sobre o objeto território urbano, mas também sobre o próprio campo disciplinar. A questão já não é apenas o que a Psicologia tem a dizer ou a contribuir com o estudo dos territórios e territorialidades, mas como as experiências de pesquisa nesses campos-temas têm desestabilizado, tensionado e modificado nossos saberes e suas formas de construção.

Isso que podemos considerar uma inversão da relação entre campo de saber e objeto, se configura por proposições teórico-metodológicas que inventam estratégias a partir das experiências advindas do processo de pesquisa. Numa perspectiva que se aproxima do que propõem Nogueira, Hissa e Silva (2015), defendemos que "toda metodologia há de ser transgressão” (p. 354). É necessário infringir o modo de funcionamento do mundo para tentar problematizá-lo, é preciso profanar as regras que ordenam o modo de funcionamento do pensamento, de suas teorias e metodologias, pois, "se o mundo está em constante movimento, em devir incessante, por que nosso modo de olhar insiste em querer paralisá-lo?" (p. 355).

No campo da Psicologia, trabalhos como o de Nogueira et al. (2015) e de Silva (2018) apontam e operam com práticas não instituídas, não oficiais, mas relevantes para a pesquisa em territórios urbanos. Caminhar, narrar, rememorar, catar restos, vão constituir pesquisas-experiências que ampliam nossas ferramentas, nossos territórios e nossas formas de mobilidade acadêmica.

Contudo, a despeito das trajetórias já percorridas pela Psicologia, não se esgotam questionamentos sobre como produzir um conhecimento que leve em consideração a experiência subjetiva de quem transita nas cidades e nos territórios acadêmicos contemporâneos. Diante da complexidade das questões que compõem o cotidiano (urbano e acadêmico), atualizam-se sempre interrogações como: de que ferramentas dispomos para abarcar a experiência dos sujeitos na cidade, sem nos rendermos e aos modelos prescritivos da produção científica? Até onde podemos transgredir nas escritas, nos métodos e nos resultados? Como podemos ocupar o território acadêmico com as questões postas pelos territórios urbanos, de modo a compor outras alianças e modos de circulação e mobilidade na ciência e na cidade?

Entendemos que tais perguntas não podem ser esgotadas e tampouco permitem respostas únicas. No intuito de contribuir com essas reflexões, trazemos aqui considerações sobre uma possibilidade teórico-metodológica inspirada pelo movimento Internacional Situacionista e constituída a partir dos dilemas e desafios colocados por uma proposta de pesquisa em um espaço urbano contemporâneo, levando-nos à noção da pesquisa-experiência. Como percorrer a cidade e sentí-la, como compartilhar essa experiência no território acadêmico, como escrever, narrar e transformar o próprio campo de conhecimento por meio desses percursos? A relação imbricada da Psicologia com a vida social e todos os seus aspectos se apresenta ao mesmo tempo como um desafio e uma potência na constante reformulação e atualização de nosso campo de saber. 


\section{Territórios urbanos, afetos e corpos}

As cidades, para Guattari (2006), são imensas máquinas produtoras de subjetividades individuais e coletivas. Para Santos (2002) elas conjugam materialidades e relações sociais. A materialidade dos espaços traz a presença dos tempos na constituição da paisagem urbana: seus prédios, praças e objetos, articulando passado e presente nas práticas sociais. O espaço pode, assim, coordenar e ser co-habitado por diferentes temporalidades e sujeitos. Cidades compõem-se por pessoas, coisas, movimentos, ruídos, cheiros, interdições, restos, passagens, permanências, memórias, sinais, cores, promessas de desenvolvimento, temporalidades, corpos, afetos, conflitos...

Tamanha complexidade torna impossível apreender as cidades em todas as suas dimensões e ingênuo pensá-las como unidades coesas. Mais do que cenários de nossas experiências cotidianas, são constituintes de nossas possibilidades de experimentá-las: "Será seguro andar por aqui?", "Até que horas podemos ficar na rua?", "Esse lugar é estranho", “Aqui me sinto bem!". Tais questões que nos interpelam como cidadão(ã)s comuns não se dissipam quando nos colocamos na cidade imbuído(a) s do propósito de pesquisar. Pesquisar na cidade é habitar e circular por territórios que nos constituem, no presente, com inúmeras marcas de um passado, sejam elas lembranças ou esquecimentos (Silva, 2018). É colocar-se inteiro, como corpo e sujeito, em uma relação com o lugar que envolve razões, desrazões e afetos. Esse emaranhado de elementos que constituem o espaço urbano desampara as pretensões de sua captura e representação como verdade por nosso conhecimento científico.

Porém, se nos territórios urbanos os afetos se evidenciam marcando nossas relações com o espaço, no território acadêmico, por sua vez, convencionou-se hegemonicamente o destaque à razão e o desprezo aos afetos. Com exceção do que podemos encontrar nos círculos de discussão de epistemologias contra-hegemônicas, pelo menos três figuras clássicas costumam sobressair-se quando se enuncia a palavra ciência: laboratório, cientista e objeto a ser estudado. Aprendemos na escola, com os filmes e, infelizmente, até mesmo na universidade que a ciência é essa busca da verdade pura, onde cientista (uma figura neutra, que transpira conhecimento e curiosidade sobre o mundo que o cerca), em seu laboratório (lugar asséptico e com variáveis controladas) vai descobrir a ver- dade sobre um determinado objeto (uma entidade passiva, que aguarda ter seus segredos revelados pelo(a) cientista perspicaz).

O encontro de quem quer fazer pesquisa com os territórios urbanos estilhaça essas imagens. Não há pureza, controle ou assepsia. Não resta, tampouco, um objeto passivo. Os movimentos, os barulhos, as memórias, os sentimentos, uma multiplicidade de elementos, enfim, desafiam todos os sentidos e certezas. Pesquisar na cidade é deixar-se conduzir por ela.

Haraway (1995) já nos alertava em 1988 que a ideia de objetividade e de método científico são fábulas contadas a estudantes dos primeiros anos de iniciação e que nenhum praticante das altas artes científicas jamais seria apanhado seguindo à risca os pressupostos pautados nos manuais de ciência. Haraway nos advertiu o quanto as ideologias oficiais sobre a objetividade e o método científico são péssimos guias no que dizem respeito a como o conhecimento científico é fabricado. Até porque, as únicas pessoas que acabam realmente por acreditar e agir a partir das doutrinas ideológicas da objetividade científica descorporificada, presente nos manuais elementares e na literatura de divulgação da tecnociência, são não cientistas. Para Haraway (1995), "a ciência é um texto contestável e um campo de poder" (p. 11).

Deparamo-nos, então, com os limites da objetividade científica e das figuras clássicas relacionadas à ciência, há tempos questionados pelas ciências humanas (entre elas a Psicologia), a partir de aspectos epistemológicos, éticos e políticos. Nos entrelaces das pesquisas nos territórios urbanos, somam-se a esses questionamentos outros, que interrogam se é possível ocupar os territórios urbanos e acadêmicos com outras imagens e práticas na produção do conhecimento.

Acreditamos que sim e, sem abdicar da razão e sobretudo de ferramentas conceituais que nos amparem, propomos aqui a ampliação do lugar do afeto e da experiência, proposta que, embora não seja absolutamente inédita, precisa ser insistentemente reafirmada e inventada como política contra-hegemônica de pesquisa na Psicologia. Desse modo, consideramos relevante o diálogo com o que tem sido produzido por outras áreas de conhecimento que como a nossa têm se interrogado sobre esses aspectos.

Iniciamos esse diálogo com Favret-Saada (2005), etnógrafa francesa, que põe em análise a questão 
do afeto na antropologia, afirmando que em geral, ignora-se ou nega-se o lugar do afeto na experiência humana. Para Favret-Saada, "aceitar ser afetado supõe, todavia, que se assuma o risco de ver seu projeto de conhecimento se desfazer. Pois se o projeto de conhecimento for onipresente, não acontece nada" (2005, p. 160). Essas questões nos provocam a pensar sobre como somos afetados diariamente pela cidade, por suas ruas, seus cheiros, seus sons, por seus habitantes junto a seus medos e sonhos. Para além disso, nos fazem interrogar sobre como a cidade afeta nossos saberes, nossa ciência.

Particularmente, para a Psicologia, os territórios se tornam alvo de interesse não por uma suposta objetividade geográfica que desenha fronteiras e esquadrinha as cidades em regiões ou bairros com valores financeiros e funcionais distintos. O que entrelaça a Psicologia ao estudo dos territórios é a dimensão humana que se compõe na relação território-subjetividade: como pessoas se constituem e constituem esses territórios como espaços de vida, trabalho, afetos, de valores culturais, políticos e morais que nem sempre convergem para os interesses da cidade como mercadoria. As produções de desigualdades, exclusões e violências atreladas à crescente financeirização do espaço urbano, também comporão, assim, o escopo das pesquisas em Psicologia.

O que se coloca em questão, portanto, são os modos de subjetivação e as territorialidades, bem como as políticas de vida e de morte nos espaços urbanos - não compreendidos como meros cenários, mas como materialidades arquitetônicas e políticas, ou condições de possibilidade, constituintes das relações e das formas de vida nas cidades contemporâneas. Para além da racionalidade da gestão das cidades, trata-se de pensar sobretudo que vidas se permite viver nesses espaços; como pessoas (mulheres, homens, crianças, negras, idosas, trabalhadoras, desempregadas, que vivem em casas ou nas ruas, que transitam a pé, de bicicleta, transporte público ou carro etc.) constituem suas vidas na conexão com seus territórios.

Ao enfatizarmos tais dimensões pretendemos chamar a atenção para aquilo que escapa à razão em nossas formas de habitar e transitar pelas cidades, destacando o caráter afetivo e singular das experiências de constituição dos sujeitos no espaço urbano. Assim, entendemos que existe uma neces- sidade de construir uma política de produção de conhecimento sobre as cidades que abarque o afeto e a subjetividade como elementos importantes para a construção de pesquisas nos territórios urbanos, que consiga compreender que a experiência não é meramente um elemento em relação ao qual devemos tomar precauções para que não contamine nossas pesquisas e que, portanto, precisa ser evitada. Ao contrário, temos que começar a produzir um conhecimento que seja afetado e que contemple, em suas narrativas e escritas, a nossa experiência como sujeitos que fazem a pesquisa.

Aqui, quando falamos de experiência, estamos falando de experimentação, assim como indica Nogueira (2013), que recusa o modelo de experiência tal como é prevista na ciência moderno-disciplinar, onde se busca uma experiência neutra nas pesquisas, como algo a ser controlado, reproduzido, padronizado e medido. Para a autora, experiência é experimentar, "é da ordem do afeto, portanto, de ser afetado, de entrar em contato com a vida" (Nogueira, 2013, p. 16). Só é possível, portanto, por uma vivência indissociável daquilo que nossos corpos, simultaneamente, sentem e fazem sentir nos territórios. Pesquisar é experienciar afetos nos territórios e, com nossas ferramentas teóricas e analíticas, trazer essas experiências para o campo da problematização acadêmica.

Logo, se quisermos criar novas possibilidades de pesquisa nos espaços urbanos, não nos basta, e efetivamente não há como, apenas identificar, observar, e analisar como manda a tradição científica. Trabalhar com o afeto como um instrumento de pesquisa é entender que nosso corpo e nossa subjetividade são componentes do processo de pesquisar. Ocupar e experienciar em um território - e não apenas se propôr a observá-lo - é colocar-se disponível para um bombardeio de afetações que transformam quem pesquisa. Não se trata, portanto, de colocar o outro ou o espaço como um objeto passivo em análise ou observação, e sim, construir um território acadêmico que coloque a nós mesmos, nossas sensações e pensamentos como peças importantes de um fazer analítico-científico.

Nessa perspectiva, entendemos que colocar a experiência como constituinte dos processos de pesquisa é situar nossos corpos como integrantes desses territórios. Prado Júnior, Amaral e Barbosa (2018) consideram o corpo como o primeiro terri- 
tório de incidência das relações de poder que nos constituem como sujeitos. Como tal, nossos corpos compõem o processo de pesquisa tornando possíveis e ordenando diferentes experiências na construção do conhecimento.

A pesquisadora branca de olhos azuis, proveniente do Sul do país, pesquisando com um sotaque diferente o sistema de moradia no setor sucroalcooleiro do nordeste é questionada pela trabalhadora negra: "Você não é daqui! Por acaso você é da família que comprou a usina?”. Pausa. Corpos de mulheres (branca e negra, de pesquisadora e de trabalhadora da usina) e territórios (acadêmico e de moradia da trabalhadora) se entrelaçam e afastam, se constituem delineando (im)possibilidades do diálogo na pesquisa. O que poderá ser dito a partir desse encontro/choque de corpos e territórios, na propriedade de uma família de usineiros, onde mora a trabalhadora da usina? O que se poderá conhecer? Que afetos são reciprocamente produzidos na tensão desse encontro? E se ele tivesse ocorrido em outro território? Que dúvidas e certezas estão aí enunciadas? O que afirmam esses corpos, antes mesmo que qualquer coisa seja dita?

O jovem pesquisador com o corpo tatuado vê outros jovens, talvez com idades próximas a sua, sendo abordados pela polícia numa rua destinada ao lazer em uma capital do nordeste. Mas mesmo assim o jovem pesquisador caminha sem ter medo de ser abordado pela polícia, pois sabe ser algo improvável de acontecer, mesmo tendo a cor da pele muito semelhante aos jovens que estão sendo revistados, mesmo tendo o corpo marcado com tatuagens como aqueles que estão sendo parados pela polícia. Isso faz o pesquisador questionar quais são as marcas que seu corpo carrega que o fazem ser visto como um corpo inofensivo ao aparato policial, enquanto os corpos parados pela polícia a sua frente, são entendidos como corpos potencialmente perigosos. Seriam suas roupas? Seu jeito de andar? De falar? São esses os elementos que diferenciam os corpos de serem alvos de intervenções policiais ou de passarem despercebidos na multidão?

Fragmentos de experiências de corpos em territórios ao mesmo tempo estrangeiros e familiares escancaram como marcas (de gênero, idade, cor, raça, classe...) produzem, reciprocamente, isso que chamamos de afetos na pesquisa. A atenção a esses afetos - que dependendo da perspectiva, podem ser considerados como elementos que interrompem o fluxo normal da pesquisa - é o que buscamos valorizar ao propormos a pesquisa-experiência. Em termos práticos, trata-se de trazer a tensão dessas experiências, dentre tantas outras que constituem o cotidiano da pesquisa, para primeiro plano, não como um contratempo ou estorvo, mas como um analisador do que se produz nos encontros entre certos corpos e territórios. Trazer a experiências dos corpos e suas marcas identitárias nos percursos de pesquisa é também uma forma de enfrentamento das hegemonias (de cor, gênero e classe) nos territórios acadêmicos e de questionamento dos silenciamentos epistemológicos, que mesmo com as melhores das intenções de transformação social, seguimos produzindo.

Tais experiências reiteram a posição de autores como Baptista e Ferreira (2012), que sustentam que há um processo simultâneo de constituição dos territórios e das subjetividades. Assim, o modo como posicionamos nossos corpos nos territórios também vai traçar as trajetórias possíveis para a pesquisa e nos convoca a refletir sobre como nos situamos nessa relação entre territórios, subjetividades e conhecimento. Não há como pesquisar nos territórios sem nossos corpos, os afetos que esses corpos produzem e o modo como são afetados.

Do mesmo modo que esses pequenos fragmentos de percursos de pesquisa nos interrogam, a imagem que Certeau (1998), do alto do World Trade Center, em Nova York, usa para questionar a maneira como nos conectamos com a cidade também nos provoca a pensarmos sobre nossos corpos em sua relação com os territórios urbanos.

Subir até o alto do World Trade Center é o mesmo que ser arrebatado até o domínio da cidade. O corpo, não está mais enlaçado pelas ruas que o fazem rodar e girar segundo uma lei anônima: nem possuído, jogador ou jogado, pelo rumor de tantas diferenças e pelo nervosismo do tráfego nova-iorquino. Aquele que sobe até lá no alto, foge à massa que carrega e tritura em si mesma toda identidade de autores ou de espectadores (Certeau, 1998 , p. 170).

Ver a cidade do alto o colocava numa posição de vouyer, distante dos amontoados de corpos que trafegam na cidade, longe do barulho incessante dos 
seus transeuntes. O êxtase de ler a cidade de cima, ou a "erótica do saber" (p. 70) como coloca Certeau, nos põe distante da cidade, e inviabiliza o encontro ou o choque entre os corpos.

Durante seu trajeto da subida do World Trade Center, Certeau se deparou com um cartaz no $110^{\circ}$ andar, que continha os dizeres "It's hard to be down when you're $u p^{\prime 2}$. Esse lugar de olhar a cidade do alto com um poder onividente de um deus que olha para sua cidade-panorama é um lugar tentador para quem pesquisa, já que é difícil ficar para baixo quando se está em cima.

Mas esse lugar do alto não nos serve para pensar a experiência cotidiana das nossas cidades. A cidade panorama é um simulacro teórico, ou seja, visual, "é um quadro que tem como condição de possibilidade um esquecimento e um desconhecimento das práticas" (Certeau, 1998, p. 171). Para o autor, a cidade panorama de um deus voyeur acaba por excluir-se dos entrelaçamentos dos comportamentos do dia a dia e se torna cada vez mais estranha a eles. Por isso, temos que pensar em uma cidade "de baixo".

[...] embaixo, a partir dos limiares onde cessa a visibilidade, vivem os praticantes ordinários da cidade. Forma elementar dessa experiência, eles são caminhantes, pedestres, Wandersmäner, cujo corpo obedece aos cheios e vazios do "texto" urbano que escrevem sem poder lê-lo. Esses praticantes jogam com espaços que não se veem; têm dele um conhecimento tão cego como no corpo a corpo amoroso. Os caminhos que se respondem nesse entrelaçamento, poesias ignoradas de que cada corpo é um elemento assinado por muitos outros, escapam à legibilidade. Tudo se passa como se uma espécie de cegueira caracterizasse as práticas organizadoras da cidade habitada (Certeau, 1998, p. 171).

E o que significa pensar a cidade a partir de uma perspectiva de baixo?

Para Reis (2017), diferente da perspectiva totalizadora do alto, na perspectiva de baixo, quem caminha vê a cidade em fragmentos. "O caminhante experiencia a cidade do comum, produzida a partir dos seus encontros com a vida urbana. Diferente do espectador das alturas, o habitante da cidade segue os caminhos sinuosos e labirínticos" (Reis, 2017, p. 23).

Esse é um exercício difícil de realizar quando pensamos na produção de conhecimento, pois exige se afastar desse olhar de cima para baixo, desse lugar de um deus que observa sua criação, mas que não se interessa em tocá-la e nem andar ao seu lado. Contudo, mesmo com as dificuldades desse deslocamento na maneira como enxergamos nossos chamados objetos de pesquisa, é também aí que podemos visualizar a potência de um olhar diferente.

Quando olhamos nossas cidades do alto de um prédio ou de uma janela de avião que sobrevoa nosso aguardado destino, estamos afastados da materialidade que compõe as ruas e as cidades que queremos conhecer. Assim também é a construção de uma metodologia de pesquisa, precisamos pensar em propostas metodológicas que nos coloquem em contato com a complexidade e a diversidade que compõe os territórios urbanos.

\section{A cidade de caminhantes}

Do mesmo modo que Nogueira et al. (2015), apostamos no caminhar como uma estratégia que permite a quem pesquisa perceber e experienciar o quão efervescente e diversa a cidade pode ser, e mais do que isso, entender que o modelo clássico de se fazer ciência não dá conta de capturar as múltiplas singularidades dos territórios e dos sujeitos que circulam por eles.

É dessa perspectiva que propomos pensar a produção do conhecimento sobre os territórios urbanos na Psicologia, colocando nossos corpos na cidade de baixo, a cidade de caminhantes e retornando ao território acadêmico com experiências e saberes que instituem outras formas de nos movimentarmos e constituirmos. Acreditamos que dessa forma poderemos criar também na academia, um território de caminhantes, um saber de baixo.

Certeau (1998) afirma que "o ato de caminhar está para o sistema urbano como a enunciação está para a língua ou para os enunciados proferidos" ( $\mathrm{p}$. 177). Caminhar, para o autor, é dar passos que moldam os espaços, é transgredir através dos desvios os trajetos preestabelecidos como corretos, é se apropriar da cidade em que se caminha.

\footnotetext{
2 “É difícil ficar para baixo quando se está em cima” (tradução nossa).
} 
Andar pela cidade é senti-la com nosso corpo. É sentir o sol escaldante do verão sob nossas costas, é ouvir o som do mar como uma música de fundo que abafa nossos passos, é sentir raiva pelo trânsito caótico, é sentir medo ao caminhar solitariamente em ruas desertas e escuras... Andar é sentir. E com o andar, também conseguimos produzir conhecimento.

No desafio de fazer do caminhar uma aposta metodológica potente diante da proposta de pesquisa em um território urbano, nos deparamos com o movimento Internacional Situacionista. Em especial, a ideia de deriva parece-nos poder contribuir com a ampliação das possibilidades de fazer pesquisa em Psicologia considerando o percorrer, o percurso e os afetos como dimensões constituintes da pesquisa.

A Internacional Situacionista foi um grupo formado nos anos 50, composto por intelectuais e artistas europeus que lutavam contra o espetáculo e a cultura da espetacularização em geral, era um movimento contrário à não participação e à passividade da sociedade. Esse grupo acabou produzindo uma série de críticas radicais ao urbanismo da época e ao modelo de cidade contemporânea que transformava a cidade em um espetáculo e seus(suas) habitantes em passivo(a)s espectadore(a)s (Fonseca, 2008).

Para esse grupo, a principal ferramenta de luta contra a cultura do espetáculo seria a participação ativa de indivíduos em todas as esferas da vida social, principalmente na cultura. O interesse dos Situacionistas pelas questões urbanas emergiu como uma consequência da importância dada ao meio urbano como terreno de ação, de produção de novas formas de intervenção e de luta (Jacques, 2003).

Os Situacionistas caminharam reflexivamente na direção contrária dos arquitetos modernos, abandonando as ideias do planejamento de cidades e entendendo que a revolução que mudaria a sociedade - e, assim, a arquitetura - não poderia ser detonada no universo das especialidades, mas ao contrário (Nogueira, 2013, p. 40).

Esse incessante confronto da Internacional Situacionista contra uma sociedade do espetáculo, onde a banalização da vida urbana é uma constante no cotidiano das cidades contemporâneas, acabou produzindo uma série de estratégias e críticas a um modelo de vida que se baseia em um consumismo imediato e exacerbado. Como algumas das principais estratégias de reinvenção e experimentação do espaço urbano, o movimento situacionista utilizava das derivas pela cidade e da Psicogeografia.

Guy Debord, líder da Internacional Situacionista, publicou um texto em 1958, intitulado 'teoria da deriva'. Nesse texto, Debord descreveu a deriva como uma "técnica de passagem rápida por ambiências variadas" (Jacques, 2003, p. 87). A ideia da deriva é de caminhar pela cidade numa tentativa de fazer emergir questões relativas à vida cotidiana na urbe durante esse trajeto, caminhar na cidade como técnica de experimentar a cidade, de fazer parte dela.

Segundo Nogueira (2013), um andar capaz de derivar, carrega a possibilidade de se abrir ao desconhecido, ao conflito e ao inesperado, diante de um viver que se estrutura no consumo, na repetição e na aceleração que a sociedade urbana nos empurra como estilo de vida.

A proposta de derivar pela cidade está vinculada a uma tentativa de desviar das rotas previstas por uma cidade-espetáculo e de se perder na cidade. Se perder não em um sentido geográfico, de vagar sem rumo por ruas intermináveis, mas sim de ir contra os sinais predeterminados que tentam regular a vida, de ir contra o fluxo. Derivar é uma forma de transgredir as regras que nos dizem como viver, por onde seguir, o que olhar e onde devem estar nossos corpos.

Essa escolha metodológica possibilitaria a quem pesquisa "reler a cidade a partir de um posicionamento crítico que permitisse 'estranhar' as formas e os usos definidos e cristalizados e enxergar, para além destes, as múltiplas possibilidades de apropriação e criação de novos usos e convivências" (Silva, 2008, p. 6).

As derivas situacionistas, segundo Silva (2008), buscariam sempre criar experimentações que tornassem o cotidiano urbano - um lugar de fragmentação e banalidade - em um espaço de crítica e transformação, já que essa prática tem como princípio uma apropriação do espaço que ultrapassa a lógica da definição das funções.

Para o(a)s situacionistas, a prática da deriva estaria associada a uma psicogeografia. Guy Debord definiu o conceito de psicogeografia como um "estudo dos efeitos exatos do meio geográfico, conscientemente planejado ou não, que agem diretamente sobre o comportamento afetivo dos indivíduos" (Jacques, 2003, p. 65). O(A) psicogeógrafo(a) seria a pessoa que 
estuda as implicações subjetivas que o meio urbano produz nos indivíduos.

Segundo Jacques (2003), a psicogeografia seria uma geografia afetiva e subjetiva que buscaria cartografar "as diferentes ambiências provocadas basicamente pelas deambulações urbanas que eram as derivas situacionistas" (p. 23). Ou seja, a psicogeografia se interessaria por entender os efeitos que o ambiente geográfico produz nas emoções e nos comportamentos dos indivíduos. Seria através da deriva, que se conseguiria utilizar a psicogeografia como uma ferramenta de transformação das sociedades.

A ideia situacionista de olhar a cidade a partir de uma perspectiva mais subjetiva colocava em confronto a visão tradicional, geométrica e racional do urbanismo da época em que foi proposta. A partir desse olhar subjetivo da cidade, utilizando da deriva e da psicogeografia como ferramentas, os situacionistas propunham analisar as cidades não a partir de uma visão tradicional quantitativa, mas sim a partir de um olhar qualitativo e subjetivo (Monte, 2015). Com essas ferramentas, o caminhar nas cidades acaba se transformando em uma narrativa da exploração sobre as muitas cidades que podem existir no interior de uma metrópole (Fonseca, 2008).

Tentando organizar de forma didática, Monte (2015), diz que a psicogeografia pode ser entendida como uma ciência ou um método de exploração dos aspectos afetivos da cidade, utilizando a deriva como principal elemento de investigação. Essa maneira de enxergar a cidade que a deriva e a psicogeografia propõem - que nos permitem olhar a banalidade da vida cotidiana como uma ferramenta de crítica sobre as relações que estabelecemos na cidade -, é o que nos chama a atenção como uma proposta metodológica potente quando pensamos a pesquisa em Psicologia.

\section{A proposta da pesquisa-experiência}

Inicialmente pontuamos uma inversão na relação campo de saber e objeto, vinculada ao modo como, na perspectiva aqui adotada, compreendemos que nossos campos-temas não podem ser definidos como passivos diante de um campo de saber que permaneceria estável frente a seus objetos. Assumimos que nossas experiências de pesquisa têm efetivamente transformado nossas epistemologias e metodologias de pesquisa em Psicologia.

Neste momento, destacamos um segundo processo de inversão possível pela consideração dos afetos e dos corpos nas pesquisas nos territórios. Trata-se aqui de trazer para o foco da pesquisa aquilo que antes era rechaçado. Colocamos em xeque o imperativo de que para produzir conhecimento deveríamos nos debruçar sobre um objeto outro, um fenômeno externo ou, no máximo, experiências de outras pessoas (que colocaríamos em análise), evitando de todo modo a expressão da experiência subjetiva de quem pesquisa.

Nos interessa, ao contrário, pensar a possibilidade de que a pesquisa sustente-se exatamente a partir da narrativa das experiências de afetação vividas pelo(a) pesquisador(a), dando amplitude e ênfase à dimensão política desses encontros e afetos, como buscamos sinalizar com os dois fragmentos de experiências anteriormente apresentados. É essa segunda inversão que gostaríamos de enfatizar como uma alternativa epistemológica e metodológica de pesquisa nos territórios urbanos.

A pesquisa-experiência se faz, portanto, primeiro pela inserção de quem pesquisa no território, pela atenção ao percurso, ao caminhar e aos afetos desencadeados nesse ato de colocar-se como corpo singular e sensível na pesquisa. Experienciar é o ponto de partida para um segundo momento, fundamental, quando deslocamos essa experiência para nosso território acadêmico e com nossas ferramentas teórico-políticas colocamos em análise a relação territorialidades-subjetividades, para tentar produzir, como Silva (2008), sugere um conhecimento sobre o espaço urbano que leve em conta a experiência de quem transita por esse espaço. Nesse segundo momento, podemos interrogar, a partir de um domínio teórico, os afetos experienciados, nosso lugar no território pesquisado, as políticas de produção e circulação do espaço e das vidas urbanas.

Pode-se, então, pensar a escrita da pesquisa a partir de narrativas das experiência de encontro dos corpos nos diferentes territórios percorridos pelos sujeitos. Por essas experiências e narrativas é possível provocar o deslocamento nas teorias, conceitos e metodologias que constituem os territórios e territorialidades disciplinares. A pesquisa pode se fazer como uma narrativa em primeira pessoa dos afetos mobilizados nos corpos caminhantes, trazendo para o campo da problematização aquilo que é suscitado, o que mobilizam, que elementos permitem colocar em análise. Não se trata, contudo, de uma narrativa intimista e romântica da experiência subjetiva, mas de um olhar analítico e problemati- 
zador sobre como a cidade nos afeta e como interroga teorias e conceitos da Psicologia, bem como nossos territórios e posicionamentos.

É a partir dessas inversões que consideramos que mais do que um conhecimento sobre os territórios urbanos, os elementos discutidos provocam a construção de outras territorialidades no espaço acadêmico da Psicologia ao romper com prescrições hegemônicas de ordem epistemológica, metodológica e conceitual. A proposta das derivas urbanas convida-nos a pensar que também podemos derivar na academia, nos movimentarmos nesse território sem certezas, considerando a experiência e os entrelaces dessa territorialidade com nossos corpos e subjetividades.

Entendemos que, assim como os territórios urbanos, o território acadêmico também tem se constituído com cenário do espetáculo, ordenado pela lógica da aceleração, da produção e do consumo. A proposta da deriva urbana sinaliza para a academia a possibilidade do perder-se, do transgredir e do conhecer em outro ritmo e com outras linguagens. Derivar é deixar-se levar e alterar o caminho por aquilo com que nos deparamos no percurso. Quando caminhamos, nossos corpos podem circular de diversas maneiras pelos territórios que ocupamos. Conseguimos, por meio do caminhar, fugir de rotas preestabelecidas, escapando da disciplina e do controle, elementos que são considerados fundamentais para a manutenção da ordem nas cidades e na ciência.

Nesse sentido, narrar experiências de pesquisa torna-se mais que uma possibilidade, uma estratégia potente para ampliar a presença de múltiplas vozes, afetos, corpos, memórias e conhecimentos. É interessante pensar como, historicamente, legitimamos que nossas pesquisas pudessem trazer narrativas e afetos das pessoas que dela participaram, como nos casos em que fazemos entrevistas ou outras formas de conversa com participantes, mas apagamos a possibilidade de expressão da experiência de quem pesquisa. Todo um processo de higienização dos afetos e da subjetividade deveria dar lugar a uma teorização generalista, racional e neutra.
Em contraposição, a pesquisa-experiência como narrativa e problematização de um corpo afetado pelos encontros ocorridos nos territórios, se interessa pelo desconforto, pela divergência, pela dissonância e singularidade de quem faz a pesquisa. Não se sustenta a ideia de um sujeito universal, mas de uma subjetividade em processo, corporificada e atravessada por inúmeros marcadores que tornam aquela experiência única. A explicitação desses marcadores e dos afetos permite-nos analisar e compartilhar as diferenças nas formas de como produzimos o humano nos territórios, ou as diversas formas da relação territórios-subjetividades.

Como narrativas de caminhantes nos territórios de baixo (urbano e acadêmico), as pesquisas-experiências afastam-se das pesquisas-espetáculo, definitivas, feitas do alto. O que produzem está aquém e além das verdades consagradas no território acadêmico, e colocam em questão os modos de ordenação dos saberes, dos corpos, das racionalidades e dos afetos que se recusam a ceder aos projetos higienistas nas cidades e na ciências. As pesquisas-experiências constituem momentos de encontro com a outridade, são contaminadas por afetos e experiências heterogêneas que produzem maneiras diferentes de olhar os territórios, sejam eles urbanos ou acadêmicos.

Quando elegemos nossos próprios corpos como elementos indispensáveis para vivermos essas experiências, estamos performando uma concepção epistemológica que nos incita a pensar, ao mesmo tempo, sobre políticas de vida nas cidades e políticas narrativas das pesquisas urbanas, enfrentando questões como as desigualdades e violências produzidas nesses espaços. Desse modo, o conhecimento que propomos não é simplesmente algo do âmbito teórico ou proveniente de uma ascese intelectual. Ele é atravessado pela experiência dos nossos corpos situados e pelos encontros e desencontros que nos constituíram ao longo de nossas caminhadas em territórios acadêmicos e urbanos e propõe, explicitamente, o desmonte de um modo de fazer pesquisa por muito tempo considerado o único legítimo e que se sustentou na universalização de uma ficção chamada subjetividade ocidental.

\section{Referências}

Baptista, L. A., \& Ferreira, M. S. (Orgs.). (2012). Por que a cidade? Escritos sobre experiência urbana e subjetividade. Niterói, RJ: EDUFF

Certeau, M. (1998). A invenção do cotidiano: artes de fazer. Petrópolis, RJ: Vozes. 
Psicologia: Ciência e Profissão 2019 v. 39 (n.spe 2.), e225540, 100-111.

Favret-Saada, J. (2005). Ser afetado. Cadernos de Campo, 13(13), 155-161. https://doi.org/10.11606/issn.2316-9133. v13i13p155-161

Fonseca, C. G. (2008). A cidade em comunicação: Paisagens, conversas e derivas no Centro de BH (Tese de doutorado). Faculdade de Filosofia e Ciências Humanas, Universidade Federal de Minas Gerais, Belo Horizonte, MG, Brasil

Guatarri, F. (2006) Caosmose: Um novo paradigma estético. São Paulo, SP: Ed. 34

Haraway, D. (1995). Saberes localizados: a questão da ciência para o feminismo e o privilégio da perspectiva parcial. Cadernos Pagu, (5), 7-41.

Hüning, S. M., Guareschi, N. M. F., Reis, C., \& Azambuja, M. A. (2014). Subjetividades, globalização e urbanização: Novos objetos da psicologia social brasileira nos Simpósios da ANPEPP. Psicologia: Ciência e Profissão, 34(2), 460473. https:// doi.org/10.1590/1982-3703000862013

Jacques, P. B. (2003). Apologia da deriva: Escritos situacionistas sobre a cidade. Rio de Janeiro, RJ: Casa da Palavra.

Monte, L. (2015). Deriva e psicogeografia na cidade contemporânea: Experimento situacionista no centro do Recife (Dissertação de mestrado). Centro de Artes e Comunicação, Universidade Federal de Pernambuco, Recife, PE, Brasil.

Nogueira, M. L. M. (2013). Espaço e subjetividade na cidade privatizada (Tese de doutorado). Instituto de Geociências, Universidade Federal de Minas Gerais. Belo Horizonte, MG, Brasil.

Nogueira, M. L. M., Hissa, C. E. V., \& Silva, J. S. (2015). O caminhar como recurso metodológico: sobre imagem e discurso. In A. C. Reis, A. R. C. Hernandez, D. Galindo, J. Tittoni, L. L. S. Mariolino, L. A. Costa, R. L. Silva (Org), Psicologia social em experimentações: Arte, estética e imagem (pp. 354-378). Florianópolis, SC: Abrapso.

Prado Júnior, V. I., Amaral, F. B., \& Barbosa, Y. M. (2018). Epistemologia do território: A prostituição masculina em Goiânia. urbe. Revista Brasileira de Gestão Urbana, 10(2), 335-345. https:// doi.org/10.1590/2175-3369.010.002.ao14

Reis, C. (2017). Cidade e diretos humanos: O comum como exercício ético da vida urbana (Tese de doutorado). Instituto de Psicologia, Universidade Federal do Rio Grande do Sul, RS, Porto Alegre.

Santos, M. (2002). O tempo nas cidades. Ciência e Cultura, 54(2), 21-22.

Silva, R. H. A. (2008). Cartografias urbanas: Construindo uma metodologia de apreensão dos usos e apropriações dos espaços da cidade. Cadernos PPG-AU/FAUFBA, 5(esp.), 83-100

Silva, W. V. N. (2018). Territórios vulneráveis: Arquivos impróprios de uma memória em perigo (Tese de doutorado). Instituto de Psicologia, Universidade Federal do Rio Grande do Sul, Porto Alegre, RS, Brasil.

\section{Simone Maria Hüning}

Docente do Programa de Pós-Graduação em Psicologia da Universidade Federal de Alagoas. Maceió - AL. Brasil.

E-mail: simone.huning@ip.ufal.br

https://orcid.org/0000-0001-8080-7733

\section{Carlysson Alexandre Rangel Gomes}

Psicólogo e Mestre em Psicologia pelo Programa de Pós-Graduação em Psicologia da Universidade Federal de Alagoas. Maceió - AL. Brasil.

E-mail: carlysson_al@hotmail.com

https://orcid.org/0000-0001-8926-8932

Endereço para envio de correspondência:

Av. Lourival Melo Mota, S/N, Tabuleiro do Martins, Maceió - AL, Cep: 57072-970

Recebido:24/06/2019

Aceito: 19/07/2019 
Received:06/24/2019

Appoved: 07/19/2019

Recibido: $24 / 06 / 2019$

Aceptado: 19/07/2019

Como citar: Hüning, S. M., \& Gomes, C. A. R. (2019). A pesquisa-experiência na Psicologia: Corpos, afetos e experiências em territórios urbanos. Psicologia: Ciência e Profissão, 39(n.spe 2), 100-111. https://doi.org/10.1590/1982-3703003225540

How to cite: Hüning, S. M., \& Gomes, C. A. R. (2019). Experience-based research in Psychology: Bodies, affections and experiences in urban territories. Psicologia: Ciência e Profissão, 39(n.spe 2), 100-111. https://doi.org/10.1590/1982-3703003225540

Cómo citar: Hüning, S. M., \& Gomes, C. A. R. (2019). La investigación-experiencia en Psicología: Cuerpos, afectos y experiencias en territorios urbanos. Psicologia: Ciência e Profissão, 39(n.spe 2), 100-111. https://doi.org/10.1590/1982-3703003225540 